\title{
Carbon isotope fractionation during methane transport: A novel method for evaluating key parameters of shale gas
}

\author{
WENBIAO Li, SHUANGFANG LU, JUNQIAN Li
}

School of Geosciences, China University of Petroleum (East

China), Qingdao 266580, China.

Carbon isotope compositions of hydrocarbon gas have long been important indicators in the studies of its genetic type, maturity and sources ${ }^{[1]}$. In recent years, the isotope fractionation associated with gas transport, such as canister desorption and production, has gradually become the focus of attention $^{[2]}$. The characteristics of isotope fractionation are close related to the gas-in-place(GIP) content, adsorbed gas ratio, the recovery ratio of total ${ }^{[2]}$ and geochemical parameters of shale ${ }^{[3]}$, which provides a novel method for evaluating key parameters of shale gas.

We performed isothermal methane adsorption-degassing experiments on 10 shale samples collected from Sichuan Basin, China, to investigate the complete methane transport process coupled with seepage, diffusion, and adsorptiondesorption. Furthermore, the decoupling experiments were conducted to explore the isotope fractionation caused by a single effect. The results showed that methane flow driven by the pressure difference (seepage) does not induce isotope fractionation due to the simultaneous transport of ${ }^{12} \mathrm{CH}_{4}$ and ${ }^{13} \mathrm{CH}_{4}$. The carbon isotope ratio of methane $\left(\delta^{13} \mathrm{C}_{1}\right)$ become lighter and then stabilizes during diffusion. At the early stage of adsorbed gas desorption, ${ }^{12} \mathrm{CH}_{4}$ is preferentially desorbed from the surface, then $\delta^{13} \mathrm{C}_{1}$ increases with time.

Combined with the experimental understanding, we further proposed a general pattern of isotope fractionation that divides the complete shale gas production/desorption process into four stages. With the general pattern, we realized the qualitative identification of the production status of shale gas wells and provide theoretical support for optimizing production strategies by the carbon isotopic variation of produced gas.

Finally, we have established an isotope fractionation model of methane during shale gas flow in the multi-scale pore. This model has been verified by the experimental data and used to evaluate key parameters of shale gas combining the canister desorption data.

References:

[1] Dai et al. (2012). Org Geochem, 43: 103-111. [2] Xia et al. (2012). Geochim Cosmochim Acta, 77: 489-503. [3] Zhang et al. (2001). Geochim Cosmochim Acta, 66: 27232742. 